In decurrent trees, there is no single dominant stem and branches tend to curve upward so their tips are a the canopy surface. Good examples are mature Quercus spp. with wide spreading crowns. Lower branches that do not bend up still are shaded out, particularly in the forest, but the other major branches thicken so that there is no semblance of a central stem in the upper crown.

\section{Allocation mechanisms}

As branches grow, the photosynthate produced by their leaves is allocated to their own growth and to the growth of the rest of the tree. Axes with the most leaves thicken most, thus maintaining both adequate water transport capacity to the leaves and mechanical strength to support the leaves $(9,13,19)$. The ratio of sapwood area proximal to leaf surface area stays fairly constant. The constancy of the ratio reflects a feedback mechanism between the amount of leaves and the rate of wood formation producing new tracheids and vessels for water transport to replace the old ones that have been embolized and are no longer functional (19).

Axes with leaves produce the photosynthate and hormones regulating wood formation. Those axes with the most leaves produce the most materials and also transpire the most water. The hormones stimulate cambial activity. The basipetal transport of auxin restricts most of this stimulation to the sequence of axes leading from the leaves to the stem and the root system. This same sequence of axes serves as the direct channel for water transport in the reverse direction. Therefore, axes thicken in proportion to the amount of leaves they serve. They produce more wood and more transport capacity, thus maintaining the ratio of leaves to sapwood.

The feedback between leaves and wood production seems obvious, but how is the wood distributed along a series of axes many meters long and far from the leaves? Axes thicken in such a way that cells at the cambium undergo the same strains in bending all along the axis. The so-called "constant strain hypothesis" (17) suggests that wood is added preferentially to those areas along the axis where bending strains are the greatest. In addition, the axes with the most leaves and the largest bending moment would thicken the most because they would bend the most in the wind and thus develop the greatest strains in bending. There are still many unanswered questions about how a strain feedback system could interact with the feedback between leaves and wood production to ensure the proper distribution of strength and transport characteristics within the branching system of the tree.

\section{Literature Cited}

1. Blake, T. J., R.P. Pharis, and D.M. Reid. 1980. Ethylene, gibberellin, auxin and apical control of branch angle in Cupressus arizonica. Planta 148:64-68.

2. Brown, C. L., R.G. McAlpine, and P.P. Kormanik. 1967. Apical dominance and form in woody plants: a reappraisal. Amer. J. Bet. 54:153-162.

3. Brunig, E.F. 1976. Tree forms in relation to environmental conditions: an ecological viewpoint, p. 139-156. In: M.G.R. Cannell and F.T. Last (eds.). Tree physiology and yield improvement. Academic, New York.

4. Champagnat, P. 1978. Formation of the trunk in woody plants, p 401-422. In: P.B. Tomlinson and M.H. Zimmerman (eds.). Tropical trees as living systems. Cambridge Univ. Press, Cambridge.

5. Hallé, F., R.A.A. Oldeman, and P.B. Tomlinson. 1978. Tropical trees and forests. Springer-Verlag, New York.

6. Jensen, E.C. and J. N. Long. 1983. Crown structure of a co-dominant Douglas-fir. Can. J. For. Res. 13:264-269.

7. Kramer, P.J. and T.T. Kozlowski. 1979. Physiology of woody plants Academic, New York.

8. Little, C.H.A. 1970. Apical dominance in long shoots of white pine (Pinus strobus L.). Can. J. Bot. 48:239-253.

9. Long, J. N., F.W. Smith, and D.R.M. Scott. 1981. The role of Douglas-fir stem sapwood and heartwood in the mechanical and physiological support of crowns and the development of stem form. Can. J. For. Res. 11:459-464.

10. Sinnot, E.W. 1952. Reaction wood and the regulation of tree form Amer. J. Bet. 39:69-78.

11. Smith, A.R. 1984. Plants, fractals and formal language, Computer Grahics 18(3):1-10.

12. Ward, H.M. 1909. Trees. Vol V. Form and habit. Cambridge Univ. Press, Cambridge.

13. Waring, R. H., P.E. Schroeder, and R. Oren. 1982. Application of the pipe model theory to predict canopy leaf cover. Can. J. For. Res. 12:556-560.

14. Wilson, B.F. 1981. Apical control of diameter growth in white pine branches. For. Sci. 27:95-101.

15. Wilson, B.F. 1984. The growing tree. Rev. ed. Univ. of Massachusetts Press, Amherst.

16. Wilson, B.F. 1986. Apical control of compression wood action in white pine branches. Wood Sci. Technol. 20:111-117.

17. Wilson, B.F. and R.R. Archer. 1979. Tree design: some biological solutions to mechanical problems. Bioscience 9:293-298.

18. Woodman, J.N. 1971. Variation of net photosynthesis within the crown of a large, forest-grown conifer. Photosynthetica 5:50-54.

19. Zimmerman, M.H. 1983. Xylem structure and the ascent of sap. Springer-Verlag, Berlin.

20. Zimmerman, M.H. and C. L. Brown. 1971. Trees: structure and function. Springer-Verlag, New York.

\title{
Tree Branch Attachment to Trunks and Branch Pruning
}

\author{
Alex L. Shigo \\ U.S. Forest Service, Northeastern Forest Experiment Station, U.S. Department of Agriculture, P. O. Box 640, \\ Durham, NH 03824
}

The vascular cambium and the growth ring it produces are continuous from trunk to branch, but the cells formed by the cambium in the upper junction of branch and trunk deviate from the normal orientation of trunk to branch by angles approaching $90^{\circ}$. Branch tissues begin to develop before trunk tissues early in the growing season. Maturation of branch tissues proceeds basipetally. The branch

The full text of this paper appeared in Can. J. Bet. 63:1391-1401; 1985. I thank Kenneth Dudzik for the photographs and especially the montage made up of 56 photographs in Fig. 8; H. Sharon Ossenbruggen and Tess Feltes for artwork; Tom van der Zwet for samples of pear infected with Erwinia amylovora; and Kevin Smith and Philip Larson for valuable discussions on the subject. xylem is oriented downward at the branch base and encircles it to form a collar. The collar tissues meet on the trunk below the branch. This branch collar is enveloped later in the growing season by the basipetal development of trunk xylem. Xylem in the trunk collar encircles tbe branch junction. The branch is structurally attached to the trunk by a series of trunk collars that envelop the branch collars every growing season. When the trunk collar is injured or removed by branch pruning, the trunk xylem above and below the cut is rapidly and extensively infected, and decay develops. When pruning cuts do not injure or remove the trunk collar, no infections develop in the trunk xylem.

Dye movement and patterns of spread of bacterial and fungal pathogens also suggest that there is no local direct conduction between trunk xylem above a branch and within a branch. 


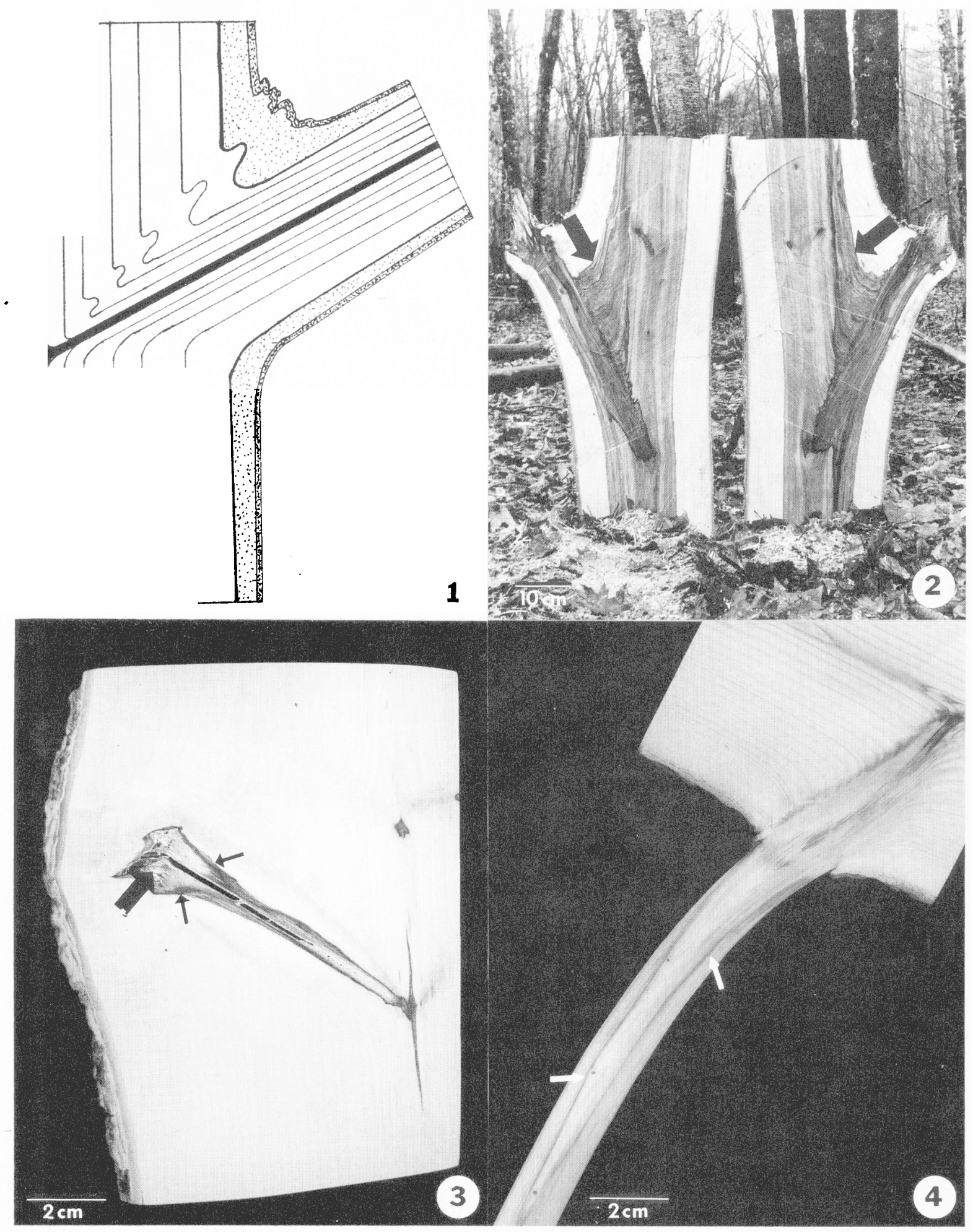

Figs. 1-4. (1) Diagram of branch-trunk junction that appears in many textbooks. The diagram shows the growth rings in the trunk above the branch continuing into the branch. At the plane of the diagram, it is difficult to understand how xylem elements in the growth rings below the branch connect with elements in the trunk above the branch. Furthermore, the diagram implies a conduction continuous from trunk tissues above a branch to the branch. Tissue arrangements below the branch are correct for the medial longitudinal view shown, but tissue arrangements are not correct when the longitudinal plane is not directly through the piths of branch and trunk. (2) Dissection of a paper birch shows that the discolored and decayed wood associated with the large branch stub was confined to the trunk wood present at the time the branch died. The infection may spread into the collar tissues that circle the branch when large columns of discolored or decayed wood spread downward into the trunk below a branch. The discolored and decayed wood may then spread slightly above the branch (arrows). (3) Dissection of a well-compartmentalized branch core in a yellow birch. The small pocket of decay at the distal end of the dead branch (large arrow) was confined by the protection zone that forms in branches (small arrows). Trees that have such strong protection zones will have sound trunk wood from cambium to pith. (4) Dissection of a hemlock shows the resin-soaked cone of wood that developed within the living branch (arrows). The resin-soaked wood is resistant to infection and the trunk is protected against invasion by pathogens. Resin-soaked cones stall shedding of the branches and, when the branch does break, it does so at the distal position of the resin-soaked cone. 


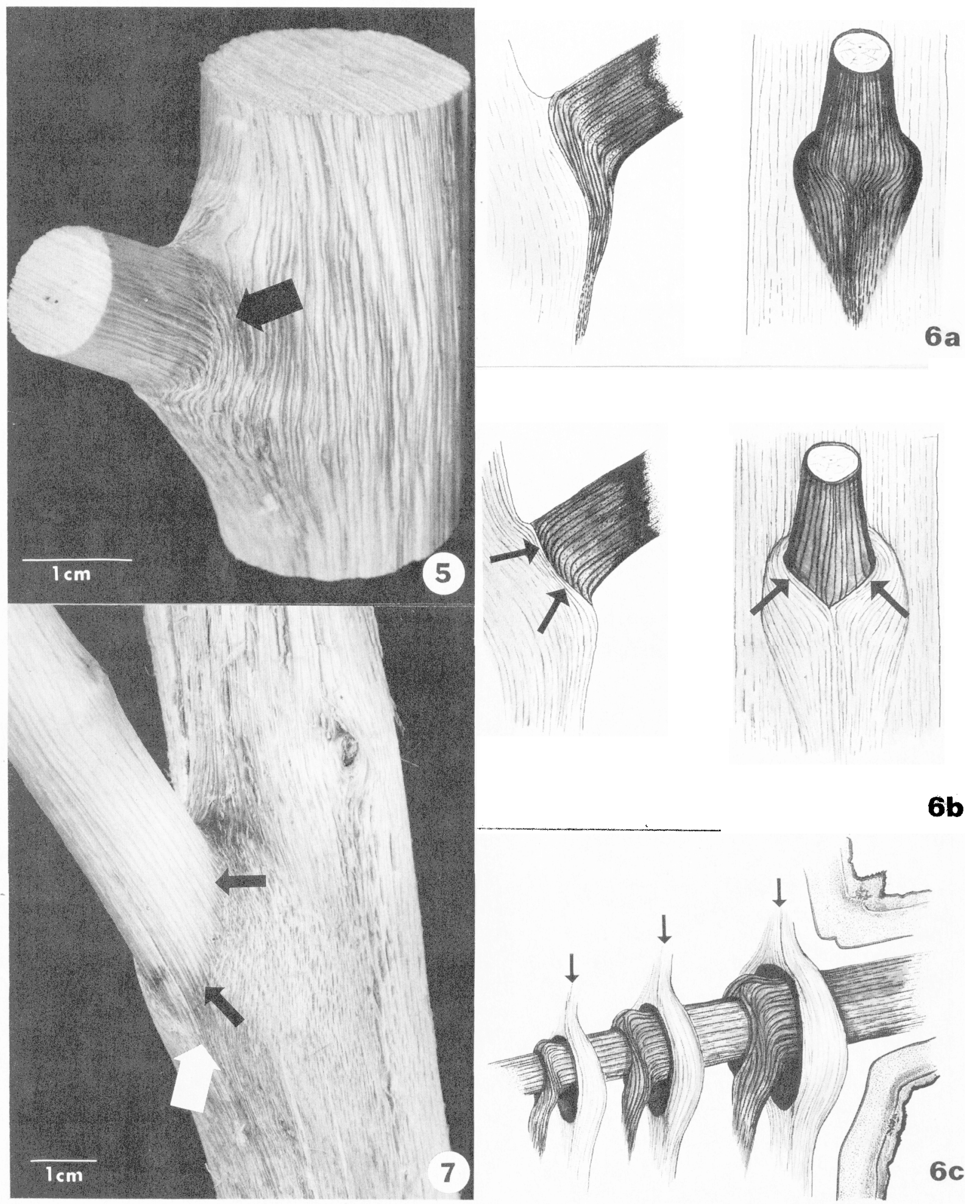

Figs. 5-7. (5) A small trunk section of red oak shows the arrangement of large spring vessels. The bark was peeled from the sample in June. The vessels turned abruptly downward at the branch base to form a branch collar (arrow). Vessels in the branch collar came together on the trunk beneath the branch. (6) Diagrammatic view of branch attachment.(a) Branch tissues develop first and form a collar about the base of the branch (dark lines)(b) Trunk tissues (arrows) later form a collar about the branch collar. Trunk collar tissues do not always meet to form a tight union below the branch. A gap in the trunk collar below the branch is common on older branches. (c) The "ball-and-socket" arrangement of the trunk collars over the branch collars can be seen if the growth rings are pulled apart. Arrows show trunk collars for each growth ring. (7) A red oak sample debarked in August. The collar of trunk wood enveloped the collar of branch wood that formed in June. Compare with (5). Black arrows show where the trunk collar enveloped the branch collar. A white arrow shows where the trunk collar may not close completely, especially in older, larger branches. 


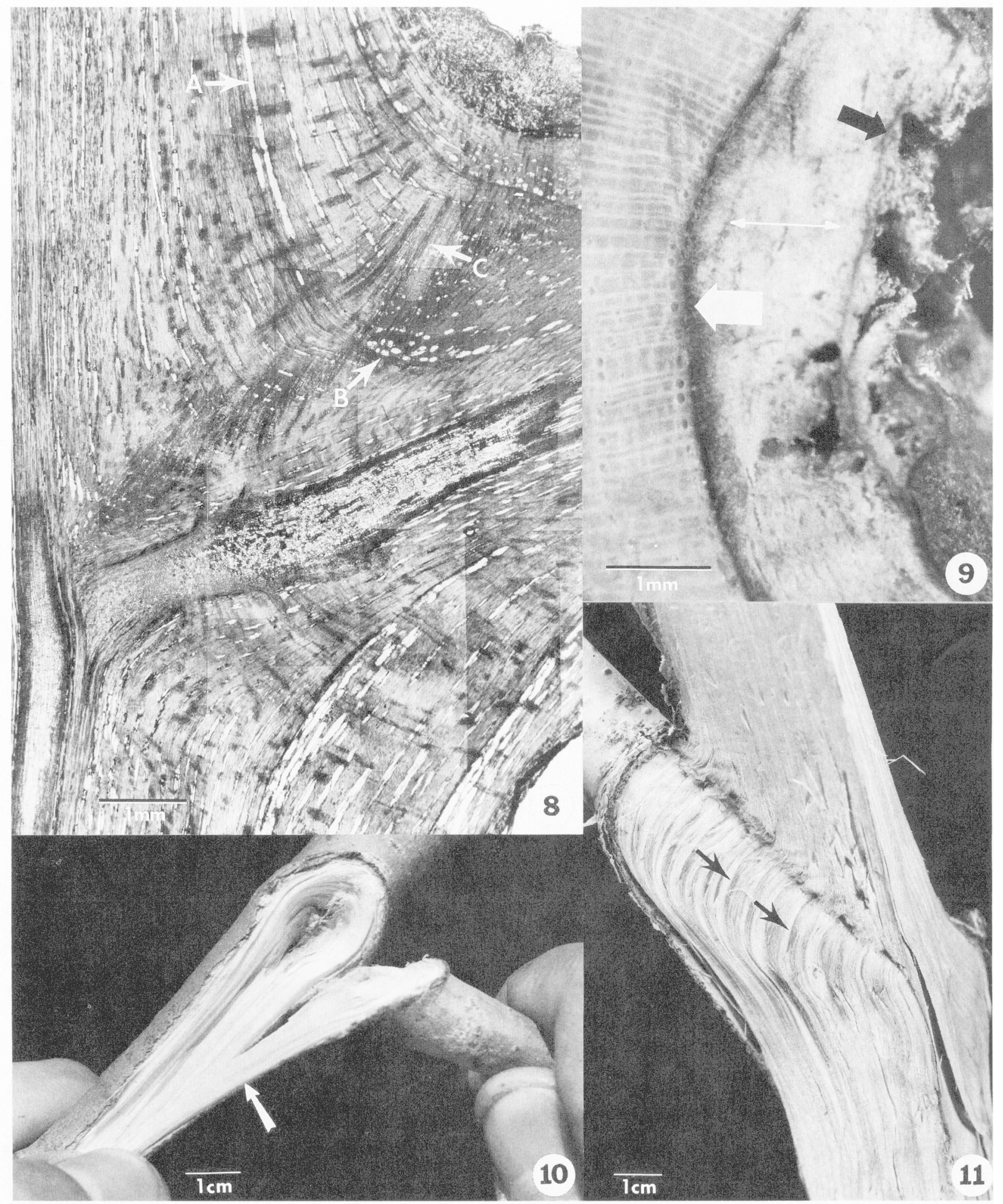

Figs. 8-11. (8) Longitudinal medial section through the branch-trunk junction of American elm shows (A) longitudinal view of the vessels in the trunk, (B) a transverse view of vessels, and (C) vascular rays at the branch-trunk junction. Vessels and rays at the junction are oriented at approximately right angles to tissues elsewhere in the trunk and branch. Note that the branch pith and the trunk pith meet but do not connect (montage of 56 photographs). (9) Close-up longitudinal view of a branch-trunk junction of an American elm made in a region similar to C in 8. Vessels and rays are cut transversely. The phloem (thin, white arrow) is greatly thickened and the phellogen (black arrow) is almost exposed to the atmosphere. The position of the phellogen makes it a possible infection court for pathogens. The cambium is shown by a thick, white arrow(10) A small branch of an aspen pulled out of the trunk shows the tissues structurally associated with the branch and trunk. The thin strip of tissues directly below the branch are connected to the branch (arrow). (11) Split section of paper birch shows curvature of trunk tissues about the branch core wood. Note the ribs or bands of high and low wood (arrows). The low bands are branch collars and the high bands are trunk ccollars. 


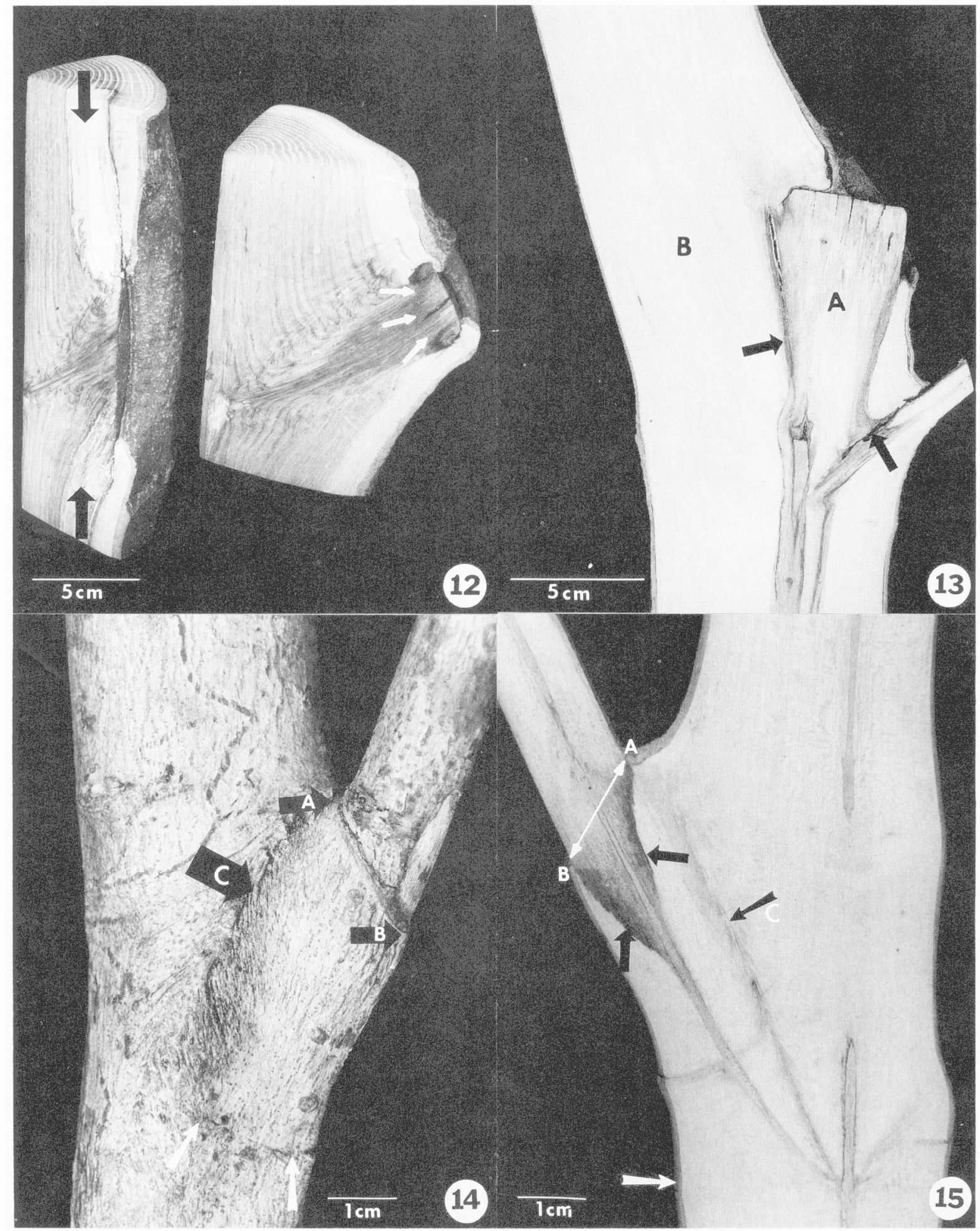

Figs. 12-15. Two samples from the same red oak that had similar-sized branches pruned 5 years earlier. At left, a pruning cut that removed the collar. Note the decayed trunk wood above and below the cut (black arrows), although the callus was large. Fungi infected the trunk wood more rapidly than the inner branch core wood. At right, a pruning cut that did not injure the collar. Infections was confined to the outer edge of the cut branch (white arrows). (13) Dissection of a (A) trunk leader stub 4 years after being cut on a red maple. The decay was confined to the old trunk wood present at the time of the cut and the new leader that formed from a (B) branch was not infected. The arrows show included bark. (14) A stub of $0.30 \mathrm{~m}$ was left after the living branch was cut on this red maple. After 1 year, the position of the trunk tissue was shown as a swollen ring about the branch base (A and B). Trunk collar tissues usually envelop the base of branches; $\mathrm{C}$, branch bark ridge. White arrows show the position of bark ridges that are maintained on the trunks of smooth-bark trees. The ridges are the lower portion of swollen rings of bark that form about the base of young, newly forming branches. Bark ridges show where branch pith meets trunk pith.(15) Dissection of the red maple in 14 shows the position of the trunk collar and the internal chemical protection zones (black arrows). A proper pruning cut to avoid trunk infection would be from A to B (white arrows); C, zone of hard compacted xylem that forms at the branch-trunk junction. When cracks format position fold inward and included bark forms where compacted xylem normally form along the zone shown by $\mathrm{C}$. The large white arrow (bottom) shows the position of the lower bark ridge shown in 14 . The center position of the bark ridge indicates the position of the internal junction of the piths of the branch and trunk. 


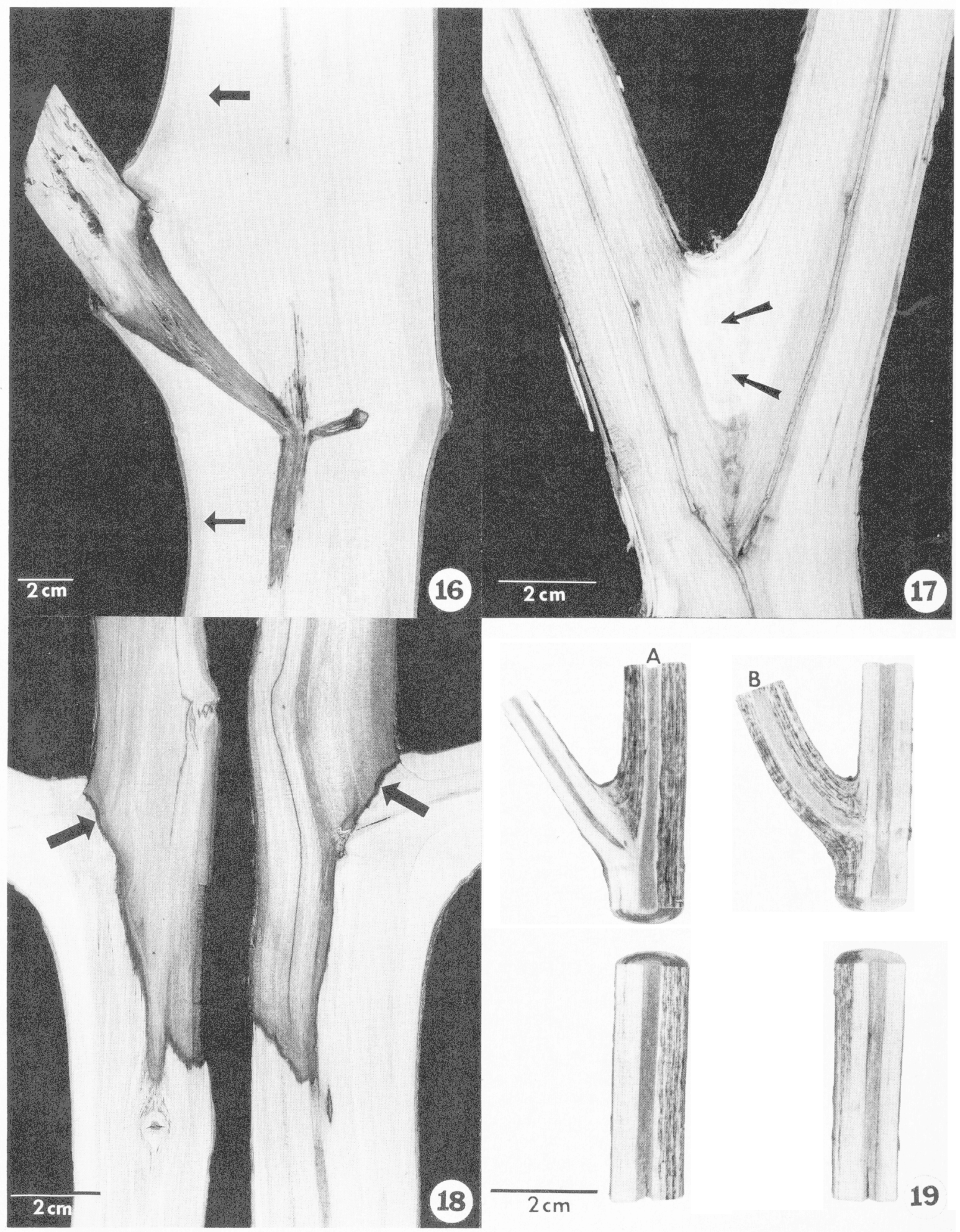

Figs. 16-19. (16) Dissection of a trunk on a red maple 7 years after a branch was cut, leaving a stub. Arrows show the size of the trunk at the time the branch was cut. Trunk tissues connected to the branch beneath the branch decreased their growth rate after the branch was cut. The stem directly beneath the branch was constricted, while the stem above the branch continued to grow at the same rate as it did before the branch was cut. (17) Dissection of an American elm infected by Ceratocystis ulmi. The branch at left was infected, but the fungus did not spread into the branch at right. The infection did not spread into the zone of compacted xylem (arrows)(18) Dissection of a pear stem infected byErwinia amylovora. The bacterium did not spread through the zone of compacted xylem into the rapidly growing branch (arrows). (19) Dissection of red maple trunks after dye was applied to the upper cut surface of a trunk (A) on one sample (left) and to the upper cut surface of the branch (B) on another sample (right). Dye did not move from trunk to branch (left) or from branch to trunk xylem above the branch (right). The thin strip of wood devoid of dye beneath the branch on the sample at left shows that the trunk collar did not close completely about the branch collar and the trunk wood directly connected to the branch. 